\title{
Atuação do Sebrae nos Ambientes de Inovação: horizonte de atuação a partir de 2019
}

\author{
Sebrae's Performance in the Innovation: environments since 2019
}

\author{
Krishna Aum de Faria ${ }^{1}$ \\ Débora Franceschini Mazzei ${ }^{1}$ \\ Juliana Ferreira Borges ${ }^{1}$ \\ Marcus Vinícius Lopes Bezerra ${ }^{1}$ \\ Sônia Marise Salles Carvalo ${ }^{1}$ \\ Adriana Regina Martin ${ }^{1}$ \\ ${ }^{1}$ Universidade de Brasília, Brasília, DF, Brasil
}

\begin{abstract}
Resumo
O Serviço Brasileiro de Apoio às Micros e Pequenas Empresas (SEBRAE) trabalha há quase duas décadas junto às incubadoras por meio de convênios de cooperação com a Associação Nacional de Entidades Promotoras de Empreendimentos Inovadores (ANPROTEC). Para dinamizar essa atuação em nível nacional, contemplando os Sebraes localizados nos 26 Estados e no Distrito Federal, criou-se, ao final de 2018, uma estratégia nacional para unificar e direcionar os esforços. O conteúdo deste artigo é uma simplificação da estratégia construída.
\end{abstract}

Palavras-chave: Sebrae. Ambientes de Inovação. Incubadoras. Anprotec.

\begin{abstract}
The Serviço Brasileiro de Apoio às Micros e Pequenas Empresas (SEBRAE) has been working closely with the incubators for almost two decades, through cooperation agreements with the National Association of Entities Promoting Innovative Enterprises (ANPROTEC). In order to stimulate this action at the national level, contemplating the Sebrae located in the 26 states and Federal District, a national strategy was created at the end of 2018 to unify and direct the efforts. The content of this article is a simplification of the strategy built.
\end{abstract}

Keywords: Sebrae. Innovation Environments. Incubators. Anprotec.

Área Tecnológica: Administração de Empresas. 


\section{Introdução}

O ambiente organizacional e suas transformações impactaram significativamente a forma como as empresas se posicionam em seus mercados competitivos nas últimas décadas. As mudanças sociais estão diretamente ligadas às mudanças tecnológicas, econômicas ou estruturais, impactando principalmente às pequenas organizações, assim como as grandes (MACHADO; CARVALHO; HEINZMANN, 2012, p. 716).

Para Lawrence e Lorsch (1967), as organizações não se posicionam mais como objeto e sim como agentes no ambiente de inovação, sendo esse um processo contínuo de flexibilidade, descentralização, horizontalização na comunicação, efetividade e rapidez nos sistemas de informação e sua utilização.

De acordo com Silva, Gonçalves e Silva (2018), a inovação é fator preponderante para o desenvolvimento de uma sociedade e do país, e, para que isso ocorra de forma sistêmica, é importante que se promovam ambientes de suporte à inovação que são definidos como Aceleradoras de Empresas (AEs), Incubadoras de Empresas (IEs) e Parques Tecnológicos (PTecs).

O Sebrae, um dos maiores apoiadores e promotores do fortalecimento dos ambientes de inovação, nasceu em 1972 como Centro Brasileiro de Assistência Gerencial à Pequena e Média Empresa (CEBRAE), a partir de uma iniciativa do Banco Nacional de Desenvolvimento Econômico e Social (BNDES) e do Ministério do Planejamento com o objetivo de representar os pequenos negócios brasileiros. Em 1992 se desvinculou da administração pública e passou a integrar o Sistema de Serviço Social Autônomo (Sistema S), transformando-se em Serviço Brasileiro de Apoio às Micros e Pequenas Empresas (SEBRAE).

O Serviço Social Autônomo caracteriza-se como entidade de direito privado sem fins lucrativos, mantido com recurso paraestatal ou dotação orçamentária. Exerce o papel de ministrar assistência ou ensino a certas categorias sociais ou grupos profissionais ligados aos setores econômicos (CAMPOS, 2016; MINAS, 2018, p. 17).

O Sebrae tem por missão "Promover a competitividade e o desenvolvimento sustentável dos pequenos negócios e estimular o empreendedorismo". Para tanto, definiu, como um dos seus principais pilares, a inovação por entender que é a mola propulsora da competitividade para os pequenos negócios. Assim, o Sebrae tem definido, como obrigatoriedade, a aplicação de $20 \%$ de seu recurso em ações de inovação e também possui abrangência nacional, sendo representado nos 26 Estados e no Distrito Federal, além de possuir uma unidade Nacional, que trabalha a estratégia a ser disseminada aos Sebraes UF (SEBRAE, 2017).

O principal parceiro do Sebrae junto aos ambientes de inovação é a Associação Nacional de Entidades Promotoras de Empreendimentos Inovadores (ANPROTEC). Segundo dados do Sebrae (2017), essa parceria iniciou-se no final da década de 1980, quando o contexto inovador era bem diferente do atual. À época, eram registradas apenas 30 incubadoras de empresas no Brasil (ANPROTEC, 2016) e o foco do Sebrae era estimular o surgimento de mais entidades 
dessa natureza. De uma maneira simplificada, a história de atuação, de acordo com o Termo de Referência do Sebrae para os ambientes de inovação (SEBRAE, 2017), resume-se em sete grandes momentos:

a) Apoio à implantação de incubadoras;

b) Aumento do número de incubadoras;

c) Fortalecimento e ampliação do número de empresas incubadas;

d)Aumento do faturamento das empresas;

e) Diversificação do portfólio de serviços ofertado pelas incubadoras;

f) Implantação do Modelo CERNE (modelo que atua conforme o nível de maturidade das incubadoras. Foi concebido para propor tanto os processos genéricos a serem implantados por uma incubadora de empresas (black box) quanto as práticas (como) que devem ser executadas para que a incubadora cumpra seu papel no ecossistema de inovação local.

g) Priorização de públicos estratégicos: negócios de impacto social, negócios com potencial de internacionalização, negócios com potencial de alto crescimento e aproximação de pequenos negócios inovadores com grandes empresas para abertura de mercado $e$ desenvolvimento tecnológico.

Há mais de 20 anos o Sebrae vem apoiando a implementação, a estruturação e a ampliação dos ambientes de inovação. Isso tem motivado reflexões sobre o modelo adequado e a estratégia de atuação do Sistema Sebrae junto às incubadoras, aceleradoras e parques tecnológicos. Por tal razão, pensou-se na elaboração de um documento balizador e inspirador que serviu como horizonte de atuação para os esforços dedicados a esse público a partir de 2019.

\section{Análises e Discussões}

Com o objetivo de observar o Sebrae como um dos agentes com poder transformador dos ambientes de inovação, a partir dos sete principais momentos de sua atuação, promoveu-se uma discussão para identificar os novos caminhos que o Sebrae poderia contribuir para o desenvolvimento e a alavancagem desse ecossistema.

De acordo com a Anprotec e Sebrae (2016), existem 369 incubadoras de empresas em todo o Brasil que reúnem cerca de 2.310 empresas incubadas e 2.815 empresas graduadas. Tais dados demonstram um processo evolutivo, não apenas em termos quantitativos, mas também qualitativos, além do aumento da complexidade na interação entre os atores do ecossistema de inovação.

De acordo com o Estudo de Impacto Econômico do Segmento de Incubadoras de Empresas no Brasil (ANPROTEC; SEBRAE, 2016), ecossistema de inovação é um termo utilizado para descrever um amplo e diversificado arranjo de participantes e de recursos que contribuem para a geração de um ambiente empreendedor ligado à inovação. Isso inclui empreendedores, investidores, pesquisadores, ambientes de inovação (incubadoras, parques, aceleradoras, coworking, entre outros), instâncias de governos etc. Alguns dos papéis desses participantes se diferenciam, conforme descrito no Quadro 1. 
Quadro 1 - Conceitos

\begin{tabular}{|c|c|}
\hline O QUE SÃo & CONCEITO \\
\hline Incubadora de empresas & $\begin{array}{l}\text { Tem o objetivo de oferecer suporte a empreendedores para que eles possam } \\
\text { desenvolver ideias inovadoras e transformá-las em empreendimentos de } \\
\text { sucesso. Para isso, oferece infraestrutura e suporte gerencial, orientando os } \\
\text { empreendedores quanto à gestão do negócio e sua competitividade. }\end{array}$ \\
\hline Parques tecnológicos & $\begin{array}{l}\text { Constituem um complexo produtivo industrial e de serviços de base } \\
\text { científico-tecnológica. Planejados, têm caráter formal, concentrado e } \\
\text { cooperativo, agregando empresas cuja produção se baseia em Pesquisa } \\
\text { e Desenvolvimento (P\&D). Assim, os parques atuam como promotores } \\
\text { da cultura da inovação, da competitividade e da capacitação empresarial, } \\
\text { fundamentados na transferência de conhecimento e tecnologia, com o } \\
\text { objetivo de incrementar a produção de riqueza de uma determinada região. }\end{array}$ \\
\hline Aceleradoras & $\begin{array}{l}\text { São entidades jurídicas (com ou sem fins lucrativos) dedicadas a apoiar } \\
\text { o desenvolvimento inicial de novos negócios inovadores (startups), } \\
\text { por meio de um processo estruturado, com tempo determinado, que } \\
\text { inclui a seleção, capacitação, mentorias, oportunidades de acesso a } \\
\text { mercados, infraestrutura e serviços de apoio, além do aporte de capital } \\
\text { financeiro inicial (próprio ou de sua rede de investidores), em troca de } \\
\text { uma possível participação societária futura nos negócios acelerados. }\end{array}$ \\
\hline Coworking & $\begin{array}{l}\text { É um modelo de trabalho que se baseia no compartilhamento de espaço e } \\
\text { recursos de escritório, reunindo pessoas que trabalham não necessariamente } \\
\text { para a mesma empresa ou na mesma área de atuação. Podem reunir } \\
\text { entre os seus usuários os profissionais liberais, empreendedores e usuários } \\
\text { independentes. É uma alternativa para aumentar a produtividade e fazer } \\
\text { novos contatos de negócios através do networking. Pessoas e empresas } \\
\text { usuárias de coworkings também utilizam esse modelo de trabalho para } \\
\text { estabelecer relacionamentos de negócios onde oferecem e/ou contratam } \\
\text { serviços mutuamente. Alguns desses relacionamentos também favorecem } \\
\text { o surgimento e o amadurecimento de ideias e projetos em grupo. }\end{array}$ \\
\hline $\begin{array}{c}\text { As instituições científicas } \\
\text { e tecnológicas (ICT) }\end{array}$ & $\begin{array}{l}\text { Em seu conceito mais amplo, envolvem universidades e institutos de pesquisa } \\
\text { públicos e privados que tenham como missão institucional, entre outras, executar } \\
\text { atividades de pesquisa básica ou aplicada de caráter científico ou tecnológico. }\end{array}$ \\
\hline Programas de aceleração & $\begin{array}{l}\text { Podem ter processos estruturados de capacitação, mentorias e, eventualmente, } \\
\text { mecanismos de acesso a mercados. Essas iniciativas diferenciam-se das } \\
\text { aceleradoras, principalmente pelo fato de serem conduzidas por entidades } \\
\text { que não são pessoas jurídicas dedicadas ao processo de aceleração. Pelo } \\
\text { fato de não investirem diretamente nas startups e, consequentemente, por } \\
\text { não assumirem participação societária nessas empresas nascentes. }\end{array}$ \\
\hline
\end{tabular}

Fonte: Elaborado pelos autores deste artigo com base em Anprotec (2019b)

A leitura desse novo cenário frente aos participantes do ecossistema nacional de inovação foi construída a partir de um esforço coletivo na Conferência da Anprotec 2018, realizada em Goiânia, GO. Foram realizadas duas reuniões de trabalho com a presença de 29 funcionários do Sistema Sebrae, representando 14 Unidades Federativas. A discussão evoluiu para a proposição de uma estratégia de atuação nos ambientes de inovação, liderada por seis Unidades Federativas do Sebrae e pelo Sebrae Nacional. 
A proposta de atuação do Sebrae está estruturada em dois pilares e cada um, por sua vez, dispõe de três eixos de atuação, conforme apresentado a seguir e demonstrado na Figura 1.

a) Pilar Mercado:

- Melhorar a integração das incubadoras ao ecossistema regional/estadual.

- Qualificar as empresas incubadas e fazer conexões para que ampliem seu potencial de mercado.

- Trabalhar o branding da incubadora.

b) Pilar Processos e gestão:

- Monitorar sistematicamente o desempenho das incubadoras e das empresas incubadas por meio de indicadores de performance.

- Contribuir com o processo de captação/alavancagem de recursos.

- Incentivar a implementação e a certificação do Centro de Referência para Apoio a Novos Empreendimentos (CERNE).

Figura 1 - Proposta de atuação do Sebrae
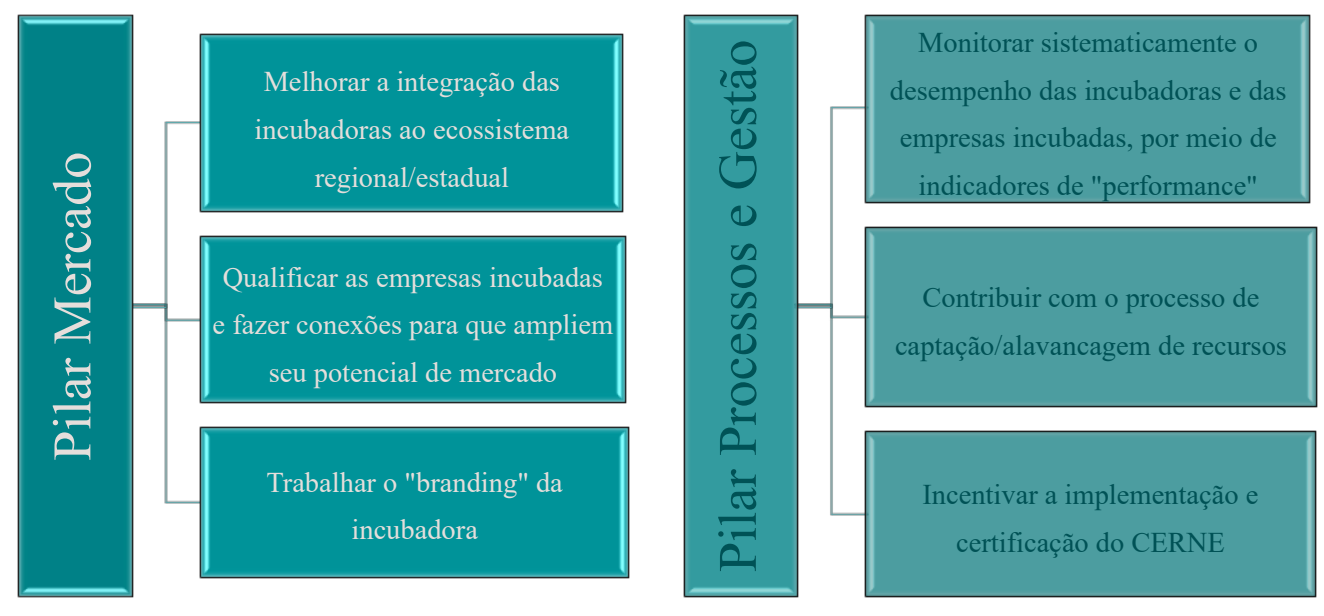

Fonte: Elaborada pelos autores deste artigo

\subsection{Pilar Mercado}

O pilar mercado refere-se ao modelo de como o Sebrae pode contribuir para dinamizar a relação dos ambientes de inovação com o ecossistema no qual estão inseridos. O objetivo é criar meios de atuação e de integração para potencializar os resultados para as incubadoras, aceleradoras e parques tecnológicos. 


\subsubsection{Melhorar a Integração das Incubadoras ao Ecossistema Regional/Estadual}

De acordo com Anprotec e Sebrae (2016), o que as incubadoras estão vivenciando chama-se de terceira geração, conforme demonstrado na Figura 2.

Figura 2 - Evolução das incubadoras no contexto

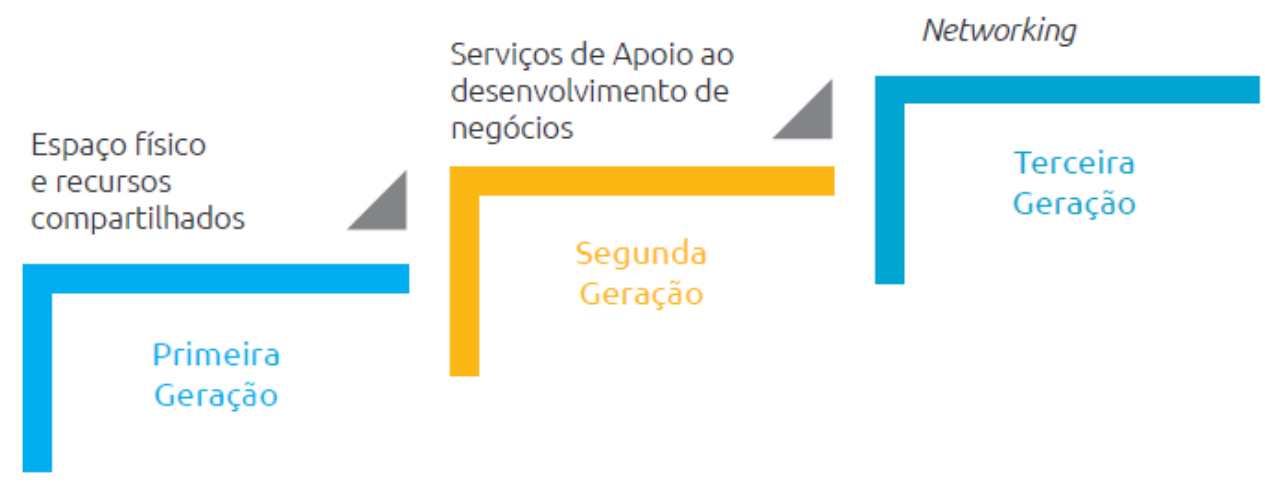

Fonte: Anprotec e Sebrae (2016)

Esse timing foca na criação e na operação de redes para acesso a recursos e conhecimentos, sintonizando a incubadora ao ecossistema de inovação no qual ela está inserida. Nesse sentido, cresce a articulação entre incubadoras de empresas e novos mecanismos de geração de empreendimentos inovadores, como as aceleradoras, os parques tecnológicos e os ambientes de coworking.

Um conceito típico dessa geração é:

[...] uma incubadora de empresas é uma organização que acelera e sistematiza o processo de criação de empreendimentos bem-sucedidos, por meio do fornecimento de um conjunto de apoios abrangentes e integrados incluindo espaço físico, serviços de suporte e oportunidades de networking e integração com clusters. (INFODEV, 2010, p. 11)

O alinhamento com a terceira geração é essencial para que as incubadoras de empresas possam atender às demandas dos novos empreendedores e empreendimentos. Ademais, também se mostra fundamental implementar as melhores práticas de atração, geração e desenvolvimento sistemático de empreendimentos inovadores.

A partir do que foi exposto, nota-se que o Sebrae pode desenvolver um importante papel de facilitador e fomentador da integração das incubadoras com os demais ambientes de inovação. Uma maneira possível para o alcance desse objetivo é fortalecer as redes de inovação estaduais e regionais, dando-lhes oportunidades e incentivos para que possam ampliar seu lócus de atuação. Nesse cenário, é fundamental estreitar o relacionamento com as mantenedoras, sejam elas universidades, prefeituras ou empresas, neste último caso, quando a incubadora for privada. Existem choques de interesses, de prioridades e de estratégias entre incubadora e mantenedor. É de suma importância que as mantenedoras percebam as incubadoras como instituições estratégicas na geração de empresas competitivas e com elevado grau de diferenciação.

Para as incubadoras vinculadas às universidades, que são a maioria no contexto brasileiro, é de suma relevância que elas passem a ser vistas pela comunidade acadêmica não como um projeto, mas como um "processo" de extensão universitária que leva ao conhecimento, à pes- 
quisa e à inovação para a sociedade (pessoas e empresas). E isso se dará a partir do momento em que as regras, que regem a progressão de um professor universitário, em nível nacional, contemplem também sua carga horária como gestor de "n" projetos incubados, da mesma forma que um "paper/artigo" é considerado. Essa articulação pode ser desenvolvida junto ao Ministério da Educação (MEC) (ensino superior), capitaneada pelo Sebrae, em parceria com a Anprotec, a Anpei, o Ministério da Ciência, Tecnologia e Inovações (MCTIC) e outros atores relevantes.

Outra frente que merece atenção, no qual o Sebrae tem uma ação concreta prevista no atual convênio com a Anprotec, é a realização de estudos regionais/estaduais do ecossistema de inovação. O resultado da análise do ecossistema de inovação fornece um panorama muito claro sobre o estágio e o potencial de cada região, possibilitando a definição de estratégias e de ações comuns para a evolução socioeconômica da região. Esses estudos podem contribuir para a implementação de políticas e de programas que propiciem o desenvolvimento social e econômico a partir do empreendedorismo e da inovação (ANPROTEC, 2019b).

A partir do que foi explanado, identificou-se algumas potenciais ações que o Sebrae possa promover:

a) Aproximação das redes estaduais/regionais de inovação para identificação de sinergias e de complementaridade.

b) Realização de Fóruns Sebrae de Inovação anuais, em nível estadual ou regional, a depender da articulação entre os Sebraes/UF e os respectivos ecossistemas locais, para promoção da inovação e integração entre os diferentes mecanismos geradores de empreendimentos inovadores (incubadoras, aceleradoras, parques tecnológicos, espaços de coworking, laboratórios de criação etc.).

c) Aproximação das mantenedoras (universidades, prefeituras e instituições privadas) para construção de um diálogo cooperado que vise a ampliar o papel da incubadora na sociedade como um agente de transformação.

d) Identificação das potencialidades e das vocações econômicas locais para induzir rotas de atuação junto aos ambientes, de maneira que cada um identifique o seu papel e que possa haver sintonia e sinergia entre as diversas frentes de atuação.

\subsubsection{Qualificar as Empresas Incubadas e Fazer Conexões para que Ampliem seu Potencial de Mercado}

O maior ativo que uma incubadora pode ter é o seu portifólio de empresas atendidas. Portanto, a seleção e o processo de oferta de consultorias e mentorias são fatores críticos de sucesso. Soma-se a isso, a sistematização de processos eficientes e eficazes de entrega de valor às empresas. 
As empresas incubadas, por maior que sejam suas densidades tecnológicas, só serão bem-sucedidas se tiverem condições de acessarem o mercado de maneira competitiva. Como uma parcela considerável das empresas incubadas pode ser classificada como startups, o Sebrae pode conectá-las a diferentes iniciativas que se apresentam por todo o Brasil. Em nível nacional, os 27 Sebraes/UF possuem projetos de atendimento a startups que podem se integrar com as cadeias de empresas incubadas.

[...] a empresa de caráter inovador que visa a aperfeiçoar sistemas, métodos ou modelos de negócio, de produção, de serviços ou de produtos, os quais, quando já existentes, caracterizam startups de natureza incremental, ou, quando relacionados à criação de algo totalmente novo, caracterizam startups de natureza disruptiva. (BRASIL, 2019)

Recentemente, o Sebrae aprovou um documento de referência para atuação em espaços de coinovação, no qual há muita aderência com a atuação de empresas incubadas, principalmente no que diz respeito à inserção de startups na cadeia de valor de grandes empresas e na conexão com investidores.

No âmbito da metodologia de gestão do Centro de Referência para Apoio a Novos Empreendimentos (CERNE), o processo de implantação das práticas e processos-chave nas incubadoras representa uma excelente oportunidade para os Sebraes/UF se relacionarem diretamente com as empresas incubadas.

[...] uma plataforma que visa promover a melhoria expressiva nos resultados das incubadoras de diferentes setores de atuação. Para isso, determina boas práticas a serem adotadas em diversos processos-chave, que estão associados a níveis de maturidade (Cerne 1, Cerne 2, Cerne 3 e Cerne 4). Cada nível de maturidade representa um passo da incubadora em direção à melhoria contínua. O objetivo do Cerne é oferecer uma plataforma de soluções, de forma a ampliar a capacidade da incubadora em gerar, sistematicamente, empreendimentos inovadores bem-sucedidos. Dessa forma, cria-se uma base de referência para que as incubadoras de diferentes áreas e portes possam reduzir o nível de variabilidade na obtenção de sucesso das empresas apoiadas. (ANPROTEC, 2019b)

A incubadora, em muitos momentos, não dispõe de portfólio de serviços adequado ao perfil de suas empresas ou não possui quadro de fornecedores habilitados para suas demandas.

Portanto, as práticas e processos-chaves previstos no Cerne podem ser correlacionados às soluções disponíveis pelo Sebrae para que possam ser atendidas. Por exemplo, no processo-chave "Qualificação" existem várias práticas-chave como "Qualificação do Empreendedor", dentre outras. Nesse caso, a solução "Empretec" oferecida pelo Sebrae, na qual desenvolve características do comportamento empreendedor, configura-se como suficiente para subsidiar à prática-chave em questão. 
Na prática, é possível estabelecer um plano de trabalho com as incubadoras a cada ano para atendimento às trilhas de capacitações chanceladas pelo Cerne para oferta de serviços diretamente às empresas incubadas.

O Sebrae/GO apresentou, conforme apresentado no Quadro 2, sugestão de integração do Cerne 1 com o portfólio de produtos e serviços do Sebrae. Ou seja, as soluções disponíveis na prateleira do Sebrae são elencadas de acordo com as áreas temáticas de atuação e distribuídas de maneira matricial, segundo os cinco processos e as 14 práticas-chave do Cerne.

Feito isso, recomenda-se uma visita in loco à incubadora para apresentar ao gestor do ambiente as soluções identificadas e validá-las para checar se fazem sentido às empresas incubadas com potencial de gerar negócio para o Sebrae/UF.

Quadro 2 - Soluções do Sebrae sob a perspectiva do Cerne

\begin{tabular}{|c|c|c|c|c|c|c|c|c|c|c|}
\hline \multirow[b]{2}{*}{$\begin{array}{l}\text { PROCESSOS } \\
\text { CERNE }\end{array}$} & \multirow[b]{2}{*}{ PRÁTICAS-CHAVE } & \multicolumn{9}{|c|}{ AçõEs } \\
\hline & & 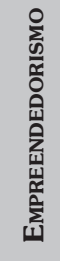 & 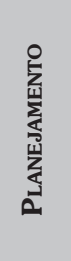 & 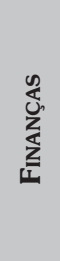 & 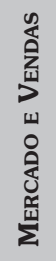 & 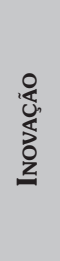 & 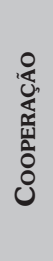 & 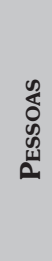 & 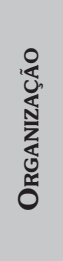 & 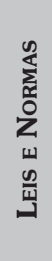 \\
\hline \multirow{3}{*}{$\begin{array}{l}\text { Sensibilização } \\
\text { e prospecção }\end{array}$} & Sensibilização & & & & & & & & & \\
\hline & Prospecção & & & & & & & & & \\
\hline & $\begin{array}{c}\text { Qualificação de potenciais } \\
\text { empreendedores }\end{array}$ & & & & & & & & & \\
\hline \multirow{3}{*}{ Seleção } & Recepção de propostas & & & & & & & & & \\
\hline & Avaliação & & & & & & & & & \\
\hline & Contratação & & & & & & & & & \\
\hline \multirow{3}{*}{$\begin{array}{c}\text { Desenvolvimento } \\
\text { do } \\
\text { empreendimento }\end{array}$} & Planejamento & & & & & & & & & \\
\hline & Agregação de valor & & & & & & & & & \\
\hline & Monitoramento & & & & & & & & & \\
\hline \multirow{2}{*}{$\begin{array}{l}\text { Graduação e } \\
\text { relação com as } \\
\text { graduadas }\end{array}$} & Graduação & & & & & & & & & \\
\hline & $\begin{array}{l}\text { Relacionamento } \\
\text { com graduadas }\end{array}$ & & & & & & & & & \\
\hline \multirow{3}{*}{$\begin{array}{l}\text { Gerenciamento } \\
\text { básico }\end{array}$} & Estrutura organizacional & & & & & & & & & \\
\hline & Operação da incubadora & & & & & & & & & \\
\hline & Comunicação e marketing & & & & & & & & & \\
\hline
\end{tabular}

Fonte: Elaborado pelos autores deste artigo 
Sugestões de iniciativas que os Sebraes/UF podem tangibilizar:

a) Identificar as soluções do Sebrae que atendam às empresas incubadas, sob a ótica do Cerne 1, e oferecer às incubadoras como forma de geração de receita para o Sebrae.

b) Integrar as áreas responsáveis pelos projetos de atendimento de startups, negócios de impacto social e pelos Agentes Locais de Inovação (ALI) aos times de inovação responsáveis pelos ambientes de inovação para que haja sinergia nas ações de atendimento.

c) Conectar as empresas incubadas com o projeto capital empreendedor, no caso dos estados que o possuírem, para acesso a investidores.

d) Conectar as empresas incubadas com espaços de inovação aberta como InovaBra, por exemplo, que possui dois colegas do Sebrae/NA alocados, para identificação de potenciais sinergias e oportunidades.

e) Conectar as empresas incubadas com os projetos de encadeamento produtivo e tecnológico (Nexos) para acesso a mercado.

f) Desenvolver ou estruturar, a partir do portfólio de soluções do Sebrae, trilhas de atendimento customizadas para as empresas incubadas.

\subsubsection{Trabalhar o Branding da Incubadora}

Segundo a Associação Brasileira de Anunciantes (ABA, 2017), entidade de classe que representa as empresas que investem em propaganda, branding é o conjunto de atividades de investigação, estratégia, criação, design e gestão de marca para coordenar suas expressões, otimizar suas relações com as partes interessadas (stakeholders) com o propósito de aumentar sua eficácia e seus valores econômico e simbólico.

O branding inclui as seguintes atividades:

a) estratégia de marcas;

b) pesquisas e auditorias de marcas;

c) identidade verbal ou naming (criação e definição de nomes e sistemas de nomenclatura);

d) design da identidade visual e ambiental;

e) comunicação da marca;

f) gestão da marca; $e$

g) valoração da marca.

A marca de uma instituição, independentemente de sua natureza, é um dos seus principais ativos, e assim também é com as incubadoras. A marca transcende o sinal gráfico, a tipografia e o nome. Uma marca é uma promessa, é associada a uma reputação e a uma entrega de valor para o mercado.

Percebe-se que no universo dos ambientes de inovação, as incubadoras não possuem uma identidade própria, uma personalidade desvinculada às suas mantenedoras. Muitas vezes, não 
possuem sequer um nome. Fala-se bastante da incubadora do parque tecnológico x ou da incubadora da universidade y ou até mesmo da incubadora no Núcleo de Inovação Tecnológico (NIT) z. Por exemplo, a incubadora de empresas do Centro de Desenvolvimento Tecnológico (CDT), da Universidade de Brasília, se chama multi-incubadora de empresas. Esse nome, do ponto de vista de marketing, não gera valor para o mercado, tampouco agrega uma personalidade forte à incubadora. Talvez, por isso, a incubadora é mais conhecida no ecossistema dos ambientes de inovação como incubadora CDT, sendo que, na verdade, o CDT é um Núcleo de Inovação Tecnológica (NIT) e não uma incubadora em si. A multi-incubadora é um dos serviços do CDT que também é responsável por outras atividades como gestão de contratos de transferência tecnológica entre a universidade e empresas, redação de patentes para pesquisadores residentes na $U n B$, entre outras.

Essa falta de identidade é prejudicial, sobretudo, para as incubadoras que não conseguem construir uma trajetória de reputação própria. O caso do CDT é um entre vários espalhados no país. A maior parte das incubadoras Brasil possui situações semelhantes. Ter um nome distinto, diferenciado, pode gerar vantagens competitivas no mercado. Alguns benefícios diretos para as incubadoras ao fortalecerem sua marca são:

a) criar um posicionamento de mercado específico, independentemente de seu mantenedor;

b) agregar valores intangíveis que possam atrair clientes aderentes à estratégia da incubadora;

c) diferenciar-se da concorrência para abertura de mercado e captação de investimentos;

d) reforçar as importantes contribuições que a incubadora pode gerar para a sociedade, seja na geração de empregos, distribuição de renda ou recolhimento de impostos.

e) romper gargalos e fortalecer o ecossistema de inovação local.

Nessa seara, o Sebrae, por meio de toda a sua expertise com gestão de marketing e de marcas, com portfólio de várias soluções relacionadas ao tema e que se encontram disponíveis em seu sítio eletrônico (www.sebrae.com.br), pode e deve prestar uma relevante contribuição às incubadoras. A seguir estão algumas sugestões de esforços que podem ser envidados:

a) promover fóruns de discussão com incubadoras e mantenedoras para sensibilização da importância de se investir em branding para posicionamento e ampliação de mercado;

b) disseminar o tema branding em incubadoras junto às redes estaduais/regionais de inovação;

c) conectar incubadoras com fornecedores de branding, sendo que muitos deles podem ser as próprias empresas incubadas e/ou graduadas;

d) identificar boas práticas internacionais de ambientes de inovação que investiram em branding e conectar com as incubadoras locais;

e) incentivar a implementação das práticas-chave do Cerne 2, mesmo que a incubadora não esteja no circuito Cerne, das práticas-chave planejamento estratégico e administração estratégica. 


\subsection{Pilar Processos e Gestão}

O pilar processos e gestão endereça às atividades que os ambientes de inovação devem ter mais foco para ampliar sua performance. Trata-se de 3 eixos que precisam ser desenvolvidos para trazer resultados mais satisfatórios para as incubadoras, aceleradoras e parques tecnológicos, bem como para suas empresas instaladas.

\subsubsection{Monitorar Sistematicamente o Desempenho das Incubadoras e das Empresas Incubadas por meio de Indicadores de Performance}

O movimento dos ambientes de inovação, em geral, e das incubadoras, em particular, tem crescido bastante nas últimas décadas. Segundo dados do Anprotec e Sebrae (2016), no início dos anos 2000 havia pouco mais de 100 incubadoras no país. Atualmente existe cerca de 400 associadas à Anprotec. Percebe-se a evolução do modelo de atuação das incubadoras ao longo do tempo. Na década de 1990, a entrega principal era o espaço físico de boa qualidade a baixo custo, além da oferta de recursos compartilhados, como auditórios, salas de reunião, equipamentos de uso comum, entre outros. Na década seguinte ampliou-se o escopo, e a contribuição principal da incubadora deixa de ser somente o espaço físico e os recursos compartilhados para enfatizar serviços de apoio ao desenvolvimento empresarial, como treinamentos, mentorias e coaching.

Atualmente, como já mencionado, estamos na terceira geração, cujo elemento central é a integração dos diferentes mecanismos de inovação: incubadoras, aceleradoras, parques tecnológicos e espaços de coworking.

Um dos maiores gaps dos ambientes é a falta de informação atualizada e tempestiva que subsidie o mercado e as entidades apoiadoras. A saber, o Sebrae, na tentativa de atualizar a sua base de dados das incubadoras em 2018, com informações relativas à quantidade de empresas incubadas, quantidade de empresas graduadas, número de empregos gerados ou impostos recolhidos, não conseguiu obter acesso a essas informações. Adiciona-se a isso a falta de monitoramento sistematizado, alicerçado em métricas e em indicadores de desempenho uniformes que sejam utilizados em nível nacional.

Sediada em Estocolmo, na Suécia, a UBI Index - que desenvolveu um índice considerado referência mundial na análise de desempenho de incubadoras ao redor do mundo - possui um menu de indicadores que já foram utilizados pelo Sebrae/PR nos quais podem comparar as performances das incubadoras em nível mundial.

Ao utilizar os indicadores similares aos do UBI, é possível pensar em algumas oportunidades:

a) utilização de indicadores internacionais de boas práticas de gestão de incubadoras no mundo;

b) medição do nível de maturidade da metodologia Cerne (benchmark) de incubadoras no Brasil;

c) elaboração de um plano de ação nacional de apoio às incubadoras para melhoria dos indicadores de resultado nesses ambientes no Brasil; 
d) utilização de um único sistema de medição e de monitoramento das incubadoras no Brasil;

e) realização da medição bianual dos resultados das incubadoras no Brasil;

f) adoção de todas as incubadoras pela metodologia de indicadores da UBI Global;

g) criação de possibilidades de incubação cruzada entre incubadoras;

h) geração de rede de especialistas internacionais para incubadoras e incubados;

i) oferecimento de visibilidade internacional dos ecossistemas do Brasil;

j) utilização de comparativo entre incubadoras de regiões distintas do país.

Além de medir a performance das incubadoras, é possível avaliar, por meio dos indicadores a serem escolhidos, os resultados das empresas nesses ambientes. O mais recomendável para a mensuração, nesse caso, é:

a) faturamento;

b) impostos sobre faturamento;

c) postos de trabalho;

d) ativos de propriedade intelectual (marcas, patentes, desenhos industriais e programas de computador); e

e) investimentos externos.

A partir do que já foi discutido, é premente que haja uma sistematização da mensuração do desempenho das incubadoras e, consequentemente, das empresas incubadas. Caberá ao Sebrae, com a colaboração dos Sebrae/UF, capitanear os seguintes esforços:

a) aferir os principais indicadores que fazem sentido para o Sebrae monitorar, tanto das incubadoras quanto das empresas incubadas;

b) criar uma estratégia nacional de monitoramento de performance de incubadoras e empresas incubadas; $e$

c) identificar fornecedores para criação de uma plataforma única de hospedagem dos indicadores.

\subsubsection{Contribuir com o Processo de Captação/Alavancagem de Recursos}

A principal dor que as incubadoras se deparam cotidianamente é a sustentabilidade financeira. Durante o Fórum Sebrae de Inovação, ocorrido em Cuiabá (MT), em 2015, Tony Chierighini, diretor da incubadora catarinense Celta, reforçou esse pensamento em sua fala no painel de abertura do evento: "A situação das incubadoras é muito vulnerável no que se refere à manutenção de sua saúde financeira". A maioria depende de recursos de editais e de subvenção econômica para manter sua saúde financeira equilibrada. O Sebrae lançou dois editais Cerne (2011 e 2015) que contemplaram 150 incubadoras nas duas edições. Pode-se dizer que esses ambientes possuem um potencial de alavancagem maior do que os demais. Porém, segundo dados da Anprotec e Sebrae (2016), existem mais de 400 incubadoras e aceleradoras no país. Portanto, a maioria desses ambientes está desprovida de condições de acesso a recursos que possam contribuir com sua performance. 
Além disso, o cenário econômico brasileiro aponta para um futuro de mais contingenciamento e restrições orçamentárias. Segundo notícias veiculadas na Revista Isto É, em maio de 2019, houve um contingenciamento de R $\$ 2,181$ bilhões no orçamento federal (ISTOÉ, 2019). Não está no horizonte do Sebrae o lançamento de novos editais ou de investimentos vultuosos direcionados aos ambientes de inovação.

O Sebrae pode articular, em parceria com a Anprotec, um movimento na Financiadora de Estudos e Projetos (FINEP) e no MCTIC, com o intuito de inserir, como prioridade, na pauta desses órgãos, a provisão de recursos financeiros para abertura de Editais para esses habitats. Paralelo a isso, é importante fomentar junto aos governos municipais, estaduais e federal a criação de políticas públicas de incentivos ao empreendedorismo inovador, apoiando NITs, ICTs, incubadoras, aceleradoras e parques tecnológicos.

Ademais, seguem sugestões de iniciativas que os Sebraes/UF podem contribuir:

a) criar um movimento nacional e/ou estadual de construção e articulação de uma política pública específica e diferenciada aos ambientes de inovação;

b) aproximar-se das Fundações de Amparo à Pesquisa (FAP) estaduais para tentar angariar recursos;

c) inserir as empresas incubadas no projeto capital empreendedor para os estados que o possuírem;

d) conectar as empresas incubadas com ações de corporate venture para aproximação com grandes empresas e investidores.

\subsubsection{Incentivar a Implementação e Certificação do Cerne}

Em 2011, na Conferência Anprotec, realizada em Porto Alegre, foi lançada a primeira versão completa dos documentos do Modelo Cerne: Sumário Executivo, Termo de Referência e Manual de Implantação Cerne 1.

A implantação do Modelo Cerne nas incubadoras foi intensificada com o lançamento do Edital Sebrae 2011. Nesse certame, foram contempladas 152 incubadoras de 20 estados brasileiros, com um total de aporte de $\mathrm{R} \$ 24.682 .163,00$ (vinte e quatro milhões, seiscentos e oitenta e dois mil, cento e sessenta e três reais).

Em 2015, o Sebrae lançou o segundo Edital, no qual foram contempladas 91 incubadoras de 17 estados brasileiros, com um total de $\mathrm{R} \$$ 18.528.975,30 (dezoito milhões, quinhentos e vinte e oito mil, novecentos e setenta e cinco reais e trinta centavos).

Portanto, o circuito Cerne mobilizou R $\$ 43.211 .138,00$ (quarenta e três milhões duzentos e onze mil, cento e trinta e oito reais) de recursos e selecionou 243 incubadoras das cinco regiões brasileiras, sendo 150 diferentes entre si. Ou seja, foi um grande esforço do Sebrae para qualificar e padronizar os processos de gestão das incubadoras.

Os dois editais lançados pelo Sebrae possuíam abrangência nacional. O formato de execução de ambos previa a formalização de convênios dos Sebraes/UF com as incubadoras dos respectivos estados. Percebeu-se, ao longo das duas experiências, que o timing de formalização dos convênios era bastante heterogêneo, seja por questões processuais internas relacionadas às 
instruções normativas do Sebrae nos estados, seja pela prioridade estratégica em nível estadual. Isso, de alguma forma, deixou o fluxo do edital como um todo desalinhado, visto que, enquanto alguns estados estavam em fase avançada de execução de seus convênios, outros ainda não tinham nem celebrado os instrumentos jurídicos.

Ademais, a metodologia do Cerne sofreu uma revisão em 2018, passando a ser mais simplificada, justamente para que a implantação das práticas e processos-chave pudesse ser realizada pelos funcionários da própria incubadora e em menor tempo.

O novo formato inclui mudança na estrutura do modelo, revisão de documentos, um site mais moderno e responsivo e três pontos essenciais:

a) Seção de tutoria: espaço para que as incubadoras associadas à Anprotec possam se inscrever e tirar dúvidas sobre o tema da vez, coordenado por um especialista.

b) Banco de boas práticas: as incubadoras que possuem a certificação Cerne apoiarão a Anprotec na organização de um banco de boas práticas que poderá ser utilizado pelos associados a qualquer momento.

c) Orientação: as rodadas de capacitações do Cerne serão mais práticas e envolverão tanto os conhecimentos quanto consultorias em grupo, nas quais os participantes poderão tirar dúvidas de acordo com suas necessidades.

Com isso, a nova edição Cerne, além de mais simples e ágil, também será menos onerosa, o que possibilitará o engajamento de mais incubadoras no processo, além da possibilidade de atração de novos parceiros interessados em apoiar financeiramente as incubadoras no custeio dessas atividades.

O novo modelo Cerne permite que as incubadoras a implantem conforme o nível de maturidade que melhor traduz o estágio da incubadora. Na prática isso significa que uma determinada incubadora, por exemplo, caso perceba que tem a preparação para tal, implante o Cerne já no nível $4 \mathrm{sem}$, necessariamente, ter que implantar nível por nível, como funcionou até o início de 2018. Isso facilita muito a adesão de mais incubadoras ao processo.

A partir do que foi discorrido neste item, sugere-se as seguintes iniciativas por parte do Sebrae:

a) promover workshops de sensibilização e de aculturamento com incubadoras que ainda não tiveram oportunidade de conhecer a metodologia Cerne;

b) incentivar a adoção do modelo Cerne pelas incubadoras; $e$

c) aproximar potenciais parceiros que possam patrocinar a certificação das incubadoras.

\section{Considerações Finais}

A estratégia criada ao final de 2018 e implementada a partir de 2019 referendou o anseio do Sebrae em adequar suas iniciativas para os ambientes de inovação de maneira que pudesse gerar diferenciais sustentáveis de longo prazo. Não fazia sentido continuar atuando de maneira descolada da realidade, visto que o momento atual exige a formação de redes e a integração dos diversos mecanismos que compõem o ecossistema nacional de inovação. 
É necessário integrar incubadoras, aceleradoras, espaços de coworking e parques tecnológicos numa ciranda que proporcione sinergia e economia de esforços. Da perspectiva de um pequeno negócio que possa ser atendido por um desses ambientes, torna-se fundamental criar uma rota de desenvolvimento tecnológico clara. Importante as empresas acessarem o mecanismo de inovação adequado, conforme seu ciclo de maturidade. Da fase de ideia até o tracionamento no mercado, passando pela validação de sua prova de conceito, estruturação das vendas e consolidação de uma carteira de clientes.

A estratégia apresentada no presente artigo, conforme demonstrado na Figura 3, procura descortinar esses horizontes criando uma proposta lógica de apoio do Sebrae. Inicia-se pela integração das incubadoras aos ecossistemas locais, respeitando suas particularidades e fortalecendo os vínculos de suporte. Sequencialmente, mapeia-se as ofertas de valor para as empresas assistidas pelos mecanismos e completa as lacunas existentes de capacitação, de mentoria $e$ de assessoramento. Depois, são fortalecidas a marca e o posicionamento de mercado das incubadoras no sentido de criar uma reputação sólida que permita a formalização de parcerias e alavancagem de recursos.

Figura 3 - Estratégia de apoio do Sebrae

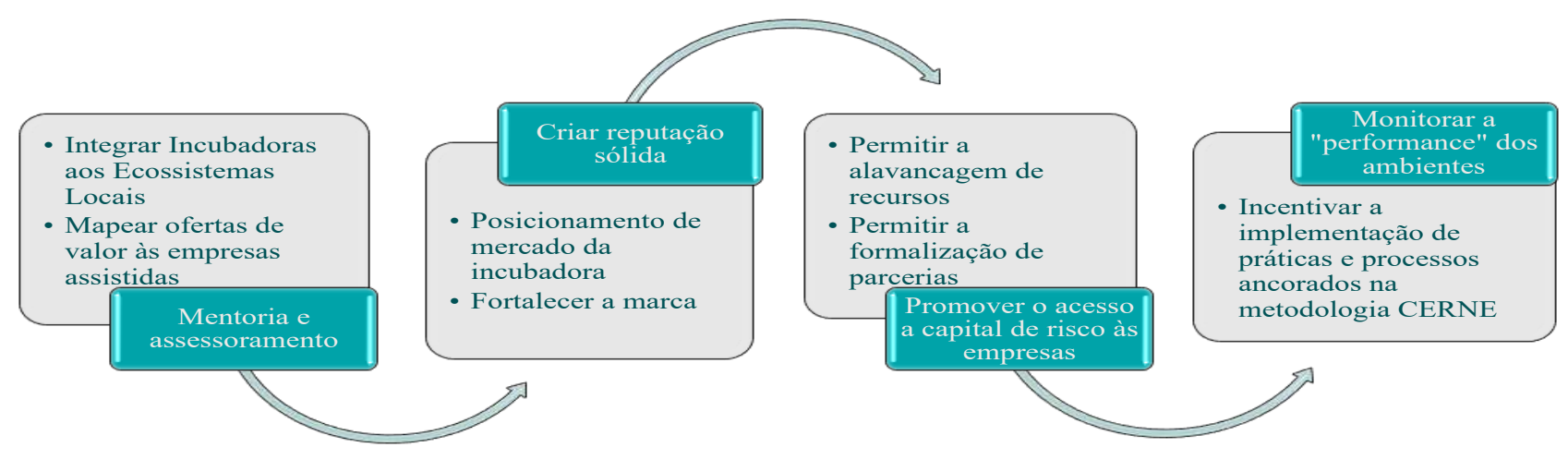

Fonte: Elaborada pelos autores deste artigo

Ademais, acrescenta-se a necessidade de monitorar a performance dos ambientes e criar uma base histórica de desempenho, na qual seja possível avaliar os avanços periodicamente. Somam-se a isso, os esforços de acesso a capital de risco aos empreendimentos que permitam gerar crescimento orgânico e sustentado. Por fim, incentiva a implementação de práticas e processos-chave de gestão ancorados na metodologia Cerne.

O que foi apresentado aqui reforça o papel do Sebrae como agente indutor de transformação e fomento ao movimento de empreendedorismo inovador. Sob a ótica da cooperação, a aliança com a Anprotec, o MCTIC, a Finep e com outras entidades de vital importância para o ecossistema de inovação revela-se oportuna e determinante para que as incubadoras, aceleradoras, espaços de coworking e parques tecnológicos possam garantir sua perenidade no mercado. 


\section{Referências}

ABA - ASSOCIAÇÃO BRASILEIRA DE ANUNCIANTES. Glossário Essencial de Branding. [2017]. Disponível em: http://www.aba.com.br/wp-content/uploads/content/7868949d15ee144fdf70f 30c5a695e22.pdf. Acesso em: 30 maio 2019.

ABREU, Isabela Brod Lemos et al. Parques tecnológicos: panorama brasileiro e o desafio de seu financiamento. Revista do BNDES, [s.l.], 2016.

ANPROTEC - ASSOCIAÇÃO NACIONAL DE ENTIDADES PROMOTORAS DE EMPREENDIMENTOS INOVADORES. Estudos. [2019a]. Disponível em: http://anprotec.org.br/site/ publicacoes-anprotec/estudos-e-pesquisas/. Acesso em: 2 jul. 2019.

ANPROTEC - ASSOCIAÇÃO NACIONAL DE ENTIDADES PROMOTORAS DE EMPREENDIMENTOS INOVADORES. Mecanismo de geração de empreendimentos e ecossistemas de inovação. [2019b]. Disponível em: http://anprotec.org.br/site/sobre/incubadorase-parques/. Acesso em: 4 jul. 2019.

ANPROTEC - ASSOCIAÇÃO NACIONAL DE ENTIDADES PROMOTORAS DE EMPREENDIMENTOS INOVADORES; SEBRAE - SERVIÇO BRASILEIRO DE APOIO ÀS MICROS E PEQUENAS EMPRESAS. Corporate venturing no Brasil: co-inovando em rede: um guia para corporações e entidades de apoio. Brasília, DF: Anprotec; Sebrae, 2018.

ANPROTEC - ASSOCIAÇÃO NACIONAL DE ENTIDADES PROMOTORAS DE EMPREENDIMENTOS INOVADORES; SEBRAE - SERVIÇO BRASILEIRO DE APOIO ÀS MICROS E PEQUENAS EMPRESAS. Estudo de impacto econômico: segmento de incubadoras de empresas do Brasil. Brasília, Anprotec; Sebrae, 2016.

ANPROTEC - ASSOCIAÇÃO NACIONAL DE ENTIDADES PROMOTORAS DE EMPREENDIMENTOS INOVADORES. Parques \& Incubadoras para o desenvolvimento do Brasil: Estudo de Práticas de Parques Tecnológicos e Incubadoras de Empresas/Ministério de Ciência, Tecnologia e Inovação - MCTI. Brasília, DF: MCTI, 2016.

BRASIL. Lei Complementar n. 167/2019, de 24 de abril de 2019. Empresa Simples de Crédito (ESC). 2019.

CAMPOS, Denise Rios. Seguro D\&O e os Serviços Sociais Autônomos: estudo de caso do SEBRAE Nacional. Caderno de Pós-graduação em Direito: Direito Societário e Globalização, Brasília, DF, UniCEUB; ICPD, 2016.

CORAL, Eliza; CAMPAGNOLO, Jorge Mário; CARIONI, Leandro (org.). Estratégias de inovação como vetor de desenvolvimento do Brasil: políticas públicas para parques tecnológicos e incubadoras de empresas. Curitiba: CRV, 2016.

HOUAISS, Antônio; VILLAR, Mauro de Sales. Dicionário Houaiss da Língua Portuguesa. Rio de Janeiro: Objetiva, 2001.

ISTO É. Contingenciamento de despesas no orçamento de 2019 é de R\$ 2,181 Bilhões.

[2019]. Disponível em: https://istoe.com.br/contingenciamento-de-despesas-no-orcamento-de-2019e-de-r-2181-bilhoes/. Acesso em: 3 jul. 2019. 
INFODEV. Global Good Practice in Incubation Policy Development and Implementation. [2010]. Disponível em: http://www.infodev.org/infodev-files/resource/InfodevDocuments_834.pdf. Acesso em: 29 maio 2019.

LAWRENCE, P. R.; LORSCH, J. W. Organization and environment: managing differentiation and integration. Boston: Harvard University Press, 1967.

MACHADO, Denise Del Prá Netto; CARVALHO Luciano Castro de; HEINZMANN, Lígia Maria. Ambiente favorável ao desenvolvimento de inovações e cultura organizacional: integração de duas perspectivas de análise. Revista Adm., São Paulo, v. 47, n. 4, p. 715-729, out.-nov.-dez. 2012. Disponível em: http://www.scielo.br/pdf/rausp/v47n4/a15v47n4.pdf. Acesso em: 14 jun. 2019.

MINAS, Raquel Beatriz Almeida de. A cultura da gestão da propriedade intelectual nas empresas: uma análise da proteção por patentes dos pequenos negócios brasileiros. 2018. 88 p. Dissertação (Mestrado - Mestrado Profissional em Propriedade Intelectual e Transferência de Tecnologia para Inovação) - Universidade de Brasília, Brasília, DF, 2018.

SEBRAE - SERVIÇO BRASILEIRO DE APOIO ÀS MICROS E PEQUENAS EMPRESAS. Termo de referência de atuação do Sistema SEBRAE junto aos ambientes de inovação. Brasília, 2017.

SEBRAE - SERVIÇO BRASILEIRO DE APOIO ÀS MICROS E PEQUENAS EMPRESAS. Termo de referência de atuação do Sistema SEBRAE em espaços de coinovação. Brasília, 2018.

SILVA, Sergio Evangelista; GONÇALVES, Carlos Alberto; SILVA, Joaquim Ramos; Venâncio, Ana Isabel Ortega. Os Papéis dos Agentes de Suporte a Empresas de Base Tecnológica. RAC, Rio de Janeiro, v. 22, n. 2, art. 3, p. 201-225, março-abril, 2018. Disponível em: http://dx.doi. org/10.1590/1982-7849rac2018170048. Acesso em: 14 jun. 2019.

\section{Sobre os Autores}

\section{Krishna Aum de Faria}

E-mail:krishna13@uol.com.br

Mestre em Propriedade Intelectual e Transferência de Tecnologia para a Inovação pela Universidade de Brasília em 2019.

Endereço profissional: Sebrae, SGAS Quadra 605, Conjunto A, Asa Sul, Brasília, DF. CEP: 70200-904.

\section{Débora Franceschini Mazzei}

E-mail: dfmazzei@hotmail.com

Mestre em Propriedade Intelectual e Transferência de Tecnologia para a Inovação pela Universidade de Brasília em 2019.

Endereço profissional: Sebrae, SGAS Quadra 605, Conjunto A, Asa Sul, Brasília, DF. CEP: 70200-904.

\section{Juliana Ferreira Borges}

E-mail: juliana.borges@sebrae.com.br

Mestranda em Propriedade Intelectual e Transferência de Tecnologia para a Inovação pela Universidade de Brasília. Endereço profissional: Sebrae, SGAS Quadra 605, Conjunto A, Asa Sul, Brasília, DF. CEP: 70200-904. 


\section{Marcus Vinícius Lopes Bezerra}

E-mail: bezerra.marcus@gmail.com

Mestre em Propriedade Intelectual e Transferência de Tecnologia para a Inovação pela Universidade de Brasília, 2019.

Endereço profissional: Sebrae, SGAS Quadra 605, Conjunto A, Asa Sul, Brasília, DF. CEP: 70200-904.

\section{Sônia Marise Salles Carvalho}

E-mail: smarises1960@gmail.com

Doutora em Sociologia pela Universidade de Brasília em 2008 e Mestre em Sociologia pela Universidade Federal do Rio Grande do Norte em 1991.

Endereço profissional: Universidade de Brasília, Campus Universitário Darcy Ribeiro, Edifício CDT, Centro de Apoio ao Desenvolvimento Tecnológico, Brasília, DF, Caixa Postal: 04397. CEP: 70904-970.

\section{Adriana Regina Martin}

E-mail: drimartin88@gmail.com

Pós-Doutora em Inovação Tecnológica pela UFSCar, 2002, Mestre e Doutora em Ciência e Engenharia de Materiais pela UFSCar, 2001. Pós-Graduada em Política e Estratégia pela ADESG. Doutorado Sandwich na Universidade de Wisconsin - Madison/USA com Bolsa Fulbright, 1999 e Bacharel e Licenciada em Química pela UFSCar. Endereço profissional: Universidade de Brasília, Campus Universitário Darcy Ribeiro, Edifício CDT, Centro de Apoio ao Desenvolvimento Tecnológico, Brasília, DF, Caixa Postal: 04397. CEP: 70904-970. 